\title{
Clinical Psychologists' Experiences of Accessing Personal Therapy during Training: A Narrative Analysis
}

\author{
Hannah M. N. Wilson* \\ Lancashire Care NHS Foundation Trust, UK \\ Stephen Weatherhead \\ Lancaster University, UK \\ Jenny S. Davies \\ Lancaster University, UK
}

\begin{abstract}
The objectives of this study were to explore the experiences of trainee clinical psychologists who utilised therapy whilst training, and its role in their personal and professional development. Ten clinical psychologists were recruited, and asked to share their story of accessing personal therapy during training. Data were analysed using narrative analysis, which led to the development of four chapters: Chapter one explores the context of being a trainee clinical psychologist whilst experiencing therapy, including stressors encountered during training. In chapter two, participants discuss the stigma they felt in accessing personal therapy. Through chapter three, participants describe the journey of therapy itself, including difficult emotions they experienced and events such as 'the ending'. Finally, chapter four details the personal and professional impact of their therapy journey. It is concluded that personal therapy can provide both personal and professional support to trainee clinical psychologists. However, some barriers may affect individuals seeking such support. The clinical and professional implications of these findings are discussed, in addition to recommendations for future research.
\end{abstract}

Keywords: clinical psychology training; narrative; personal therapy; qualitative

${ }^{*}$ Corresponding Author: Dr Hannah M N Wilson, Lancashire Care NHS Foundation Trust, UK

Email: wilson.hmn@gmail.com

Journal URL: http://e-learning.coventry.ac.uk/ojs/index.php/pblh

Wilson, H.M.N., Weatherhead, S. and Davies. J.S. (2015) 'Clinical Psychologists' Experiences of Accessing Personal Therapy during Training: A Narrative Analysis'. International Journal of Practice-based Learning in Health and Social Care, 3 (2), 32-47. doi 10.18552/ijpblhsc.v3i2.238

(C) 2015 Hannah M N Wilson, Stephen Weatherhead and Jenny S. Davies. This Open Access article is distributed under the terms of the Creative Commons Attribution Non-Commercial License 4.0 International License (http://creativecommons.org/licenses/by-nc/4.0/), which permits unrestricted noncommercial use, distribution, and reproduction in any medium, provided the original work is properly cited. 


\section{Introduction}

Personal therapy for mental health therapists is cited as an important process, which facilitates both personal and professional development (Sheikh, Milne, and MacGregor 2007). However whilst some claim personal therapy supplements therapists' learning and development in a unique way (Norcross 2005), others suggest it can have negative impacts (Atkinson 2006). For many therapists, such as counselling psychologists, accessing personal therapy during training is mandatory (British Psychological Society [BPS] 2006). Many European countries require trainee therapists to undertake a certain number of hours of personal therapy (Malikiosi-Loizos 2013). Conversely, clinical psychology trainees in the UK are not required to undertake personal therapy. The BPS Division of Clinical Psychology (2015) states on its website that 'the difference in requirements [between counselling and clinical psychology training] is historical and also due to the foundation upon which each of the programmes was developed' (Personal Therapy section). It notes that there has been a more recent move towards a 'reflexive scientific practitioner perspective' in clinical psychology training, rather than the original scientist practitioner base. There would consequently appear to be a need to explore opportunities for development in reflection and self-awareness for clinical psychology trainees.

This introduction will review potential positive and negative impacts from therapy, and whether current empirical evidence suggests any detectable effect on client outcomes. Finally, it will review the use of personal therapy by clinical psychology trainees. Throughout, the term 'personal therapy' refers to mental health therapists accessing psychological treatment (Geller, Norcross and Orlinsky 2005). This can be voluntary or mandatory, and provided by clinicians from a range of theoretical orientations.

\section{Effects of personal therapy}

Personal therapy is advocated by many psychotherapeutic approaches for both training and practising therapists (Rake 2009). In a systematic review, Orlinsky, Norcross, Ronnestad and Wiseman (2005) found $88 \%$ of 3,629 therapists from 13 countries reported positive outcomes from personal therapy. The proposed outcomes from personal therapy can be broadly grouped into: emotional support, enhanced self-awareness, and professional development.

\section{Emotional support}

Personal therapy can support therapists in managing personal and professional stressors (Daw and Joseph 2007, Norcross, Dryden, and DeMichele 1992). Surveys conducted with trainee therapists have suggested a substantial proportion of those accessing therapy are seeking, or receiving, emotional support (Bike, Norcross, and Schatz 2009, Holzman, Searight, and Hughes 1996). Trainee therapists have indicated their emotions can impact on performance, and therapy can support them through the pressures of training (Moller, Timms, and Alilovic 2009).

Whilst it seems intuitive to assume personal therapy provides emotional support to therapists, some research suggests it may create psychological distress. In their review of the literature, Macran and Shapiro (1998) claimed "despite its positive qualities personal therapy imposes a major burden, particularly for therapists undergoing training" (16). This included relationship difficulties, time and financial restraints, and preoccupation with personal conflicts. It is unknown how much this can be influenced by whether personal therapy is mandatory. Personal therapy may also "open a can of worms" (Moller, Timms, and Alilovic 2009: 379), resulting in emotional instability whilst dealing with difficulties. These experiences can be unhelpful both personally and professionally; trainees reported struggling to be "emotionally available" for clients whilst preoccupied with their own issues (Kumari 2011: 226).

\section{Enhanced self-awareness}

Some authors emphasise the importance of trainee therapists gaining self-awareness, in order to support others achieving the same (Norcross 2005). A heightened self-awareness allows 
therapists to distinguish between emotional reactions of themselves and a client, and develops a clinician's resilience (Kumari 2011). Research studies suggest a link between personal therapy and increased self-awareness (Macaskill and Macaskill 1992, Macran and Shapiro 1998). This includes acknowledging personal triggers and processing personal issues (Moller, Timms, and Alilovic 2009). Conversely, personal therapy may lead to trainees becoming preoccupied with their own experiences, rather than increasing self-awareness (Ivey and Waldeck 2013).

Thorne and Dryden (1991) state that personal therapy should not be mandatory as there is the potential for difficult emotions to arise. They emphasise the importance of readiness and choice in order for therapy to be effective. Some qualitative studies participants have expressed frustration and anger at the mandatory aspect of their therapy (Rizq and Target 2010, von Haenisch 2011). The majority of research regarding personal therapy has been conducted with samples required to access therapy. Therefore, it is unclear how much this aspect may affect participants' responses regarding the experience and efficacy of therapy overall.

\section{Professional development}

Several studies suggest accessing personal therapy provides valuable experiential learning for trainee therapists, which then impacts on their clinical practice (Grimmer and Tribe 2001, Ivey and Waldeck 2013, Kumari 2011). This includes socialisation to different approaches, and modelling opportunities (Murphy 2005, Norcross and Guy 2007, Rake and Paley 2009). Qualitative research conducted by Moller, Timms, and Alilovic (2009) suggested experiencing the client role and seeing therapy "in action" (376) was particularly helpful. However, some of the reported learning may have occurred through supervision and other opportunities, rather than being specific to therapy.

Trainee clinical psychologists interviewed by Ivey and Waldeck (2013) in South Africa also described the value of personal therapy, as "you need to know how damn hard it is sometimes to be a patient" (3). Macaskill (1999) suggests this could be accessed through peer counselling or role-play within training, but qualitative studies indicate being a client provides a unique opportunity in developing empathy (Moller, Timms, and Alilovic 2009).

\section{Impact on therapy outcomes}

Some quantitative data has supported the positive impact of personal therapy on outcomes such as therapeutic alliance and premature termination rates (Gold and Hilsenroth 2009, Greenspan and Kulish 1985). However two reviews of the literature have indicated little empirical evidence of positive effects on therapy outcomes, including therapist and client improvement ratings (Clark 1986, Macran and Shapiro 1998).

Whilst this could suggest that positive impacts of personal therapy are not translated into clinical outcomes, the majority of benefits proposed have not been quantitatively explored (Macaskill 1999). In addition, much of the published literature has been conducted without "large samples, controls, random assignment to personal therapy or nontherapy, and prospective designs" (Norcross and Guy 2007: 172). It is also difficult to quantify many of the potential impacts of personal therapy, and how these could affect client outcomes. Bellows (2007) suggests a chain effect of how personal therapy may impact on client outcomes, whereby clients witness and internalise a therapist's modelled self-acceptance and self-respect. Wiseman and Shefler (2001) suggest the personal and professional aspects of a therapist are not easily separated. Consequently, any personal benefits from personal therapy are likely to translate into positive clinical effects.

\section{Personal therapy for clinical psychology trainees}

The majority of research regarding personal therapy has been conducted with counselling psychologists or psychotherapists, with little involving clinical psychology trainees as 
participants (Timms 2010). Despite this, a number of clinical psychology trainees choose to access therapy. Nel, Pezzolesi and Stott (2012) surveyed 357 clinical psychologists within the UK; $26 \%$ accessed personal therapy during training. $88 \%$ of those rated it as important in their personal and professional development.

The lack of agreement on the utility of personal therapy for trainee therapists is reflected in British clinical psychology training programmes. Some courses are described by trainees as funding or encouraging therapy, whilst others are reported to do neither (BPS 2013). Although research regarding personal therapy is likely to be applicable to clinical psychology, there are significant differences in the training programmes. Within the UK, clinical psychology trainees are salaried, whereas psychotherapy and counselling trainees typically self-fund their training and therapy (Moller, Timms, and Alilovic 2009). Financial burden has been cited as one factor negatively impacting on the experience (Kumari 2011) but this may be less so for clinical psychology trainees. In addition, the fact that personal therapy is not mandatory during clinical psychology training may affect the motivations, expectations and experiences of those trainees who access it.

\section{Aims and rationale}

Research appears to suggest the majority of therapists who access personal therapy during their training find it beneficial; however there is a lack of information regarding the journey of undertaking personal therapy for trainee clinical psychologists. It is also unclear to what extent personal therapy is encouraged, or supported, for this professional group.

Although there have been qualitative studies regarding this topic with other groups of therapists, there is a paucity of narrative research. Squire (2008) describes how narratives, or stories, are how humans make sense of their experiences. Telling stories is purported to allow individuals to process events they have experienced, and draw meaning from them (Wertz et al. 2011). This study sought to explore participants' experiences of accessing personal therapy during training, including its impact on their personal and professional development.

\section{Method}

\section{Design}

A qualitative design was employed to enable an in-depth exploration of clinical psychologists' experiences. Narrative analysis was considered the most appropriate approach to achieve the study aims. Narrative psychology explores how individuals make meaning of their experiences and the world (Murray 2008), and posits that narration is quintessentially human (Byatt 2000). Riessman (2008) suggests using narrative methods allows participants to tell their stories, through which identity is constructed. This study sought to give voice to individuals' stories, and the way in which they understood and assimilated their experiences of personal therapy.

This study was reviewed and given full ethical approval.

\section{Sampling and participants}

All clinical training programmes within the UK were contacted to request if they would forward the study information and interest form to qualified individuals who began training in 2002 or later. 'Personal Professional Development' became a core competency of clinical psychology training in 2002 (BPS 2002), therefore it was considered more likely personal therapy was encouraged or facilitated after this date. Eleven courses agreed to circulate the information, and sixteen expressions of interest were received. Due to logistical difficulties, six of these individuals were thanked for their interest but not interviewed. The remaining ten individuals were contacted to arrange a convenient time and location for the interview. 
Demographic information regarding participants and their experiences of personal therapy is presented in Table 1.

Table 1. Demographic information regarding participants and their experiences of therapy.

\begin{tabular}{|c|c|c|}
\hline \multicolumn{2}{|l|}{ Demographics } & No. $(n=10)$ \\
\hline \multicolumn{2}{|l|}{ Gender } & \\
\hline & Male & 0 \\
\hline & Female & 10 \\
\hline \multicolumn{2}{|c|}{ Time since qualifying (years) } & \\
\hline & Mean & 2.85 \\
\hline & SD (2.d.p.) & 2.97 \\
\hline & Range & $0.5-7$ \\
\hline \multicolumn{2}{|c|}{ Stage of training when began therapy } & \\
\hline & Year 1 & 2 \\
\hline & Year 2 & 6 \\
\hline & Year 3 & 2 \\
\hline \multicolumn{2}{|c|}{ Number of therapy sessions (approx.) } & \\
\hline & Mean & 82 \\
\hline & SD (2.d.p.) & 87.44 \\
\hline & Range & $6-300$ \\
\hline \multicolumn{2}{|l|}{ Model of therapy } & \\
\hline & Integrative & 3 \\
\hline & Cognitive Analytic Therapy & 1 \\
\hline & $\begin{array}{l}\text { Psychodynamic/psychoanaly } \\
\text { tic }\end{array}$ & 6 \\
\hline \multicolumn{2}{|l|}{ Funding source for therapy } & \\
\hline & Self & 7 \\
\hline & Course & 1 \\
\hline & Both & 2 \\
\hline
\end{tabular}

\section{Interview procedures}

The interview schedule began with an open question, to increase the likelihood of narrativisation (Riessman 1993). The aim of a narrative interview is to produce detailed accounts (Riessman 2008); consequently prompts such as 'can you tell me more about that' were employed to encourage expansion. 
Each participant was provided with an information sheet before signing consent. Interviews took place at either the participant's home or workplace. All interviews were recorded and later transcribed. On completion, the debrief sheet was provided and any questions were answered. The interviews ranged in length from $52-85$ minutes.

\section{Reflexivity}

The authors believe the data cannot be fully separated from the storyteller's beliefs and interpretations (Coffey 1999, Sword 1999), and that a participant's perception of themselves and their experiences is fluid. Telling stories carries a significant social component, as there is both a teller and a hearer; they are never told the same twice (Squire 2008).

The first author was a trainee clinical psychologist and conducted each interview. Her position as a trainee may have affected participants' construction of their narratives. A reflective diary was kept by this author to acknowledge any assumptions, and discussions were regularly held with supervisors.

\section{Data analysis}

The data analysis drew upon several narrative methods and frameworks. Interview transcripts were read repeatedly to gain familiarity. Each transcript was then separated into narrative segments (Weatherhead 2011). Several aspects were explored and noted within each segment: narrative tone; imagery; characters; pace; and key themes (Crossley 2000). A summary story was written for each participant, to help ensure the final analysis captured their key events.

Each transcript was examined for common themes, characters and stories. This led to the development of shared plots, which represented the narratives across the ten transcripts. These were compared against the summary stories, to ensure no key aspects were missed. Strategies such as maintaining a full paper trail, disconfirming data analysis and comparing researchers' coding for some data were utilised to increase the rigour of the study (Yardley 2008).

\section{Findings}

The findings below represent a shared plot which emerged from the ten transcripts, and is organised into chapters. Chapters One and Two explore the context of participants' stories, whilst Chapter Three represents the journey of therapy itself. Finally, Chapter Four describes the impact and influence of therapy on participants, both personally and professionally.

\section{Chapter One: Being a trainee - 'You can take all your stresses to therapy' (Annie)}

Within this chapter, participants frequently personified 'the course' as a singular entity with demands and expectations. The course played an important role in initiating participants' personal therapy journey, with six participants indicating it was the trigger for them seeking therapy: "[you are] being stretched and being a bit more vulnerable to, to your weaknesses, because you're being scrutinised and erm, assessed" (Lilly). Incidents such as failing a placement or assignment were key events, described as catalysts for seeking therapy as ' $m y$ world had just been destroyed' (Holly). Wosket (1999) describes how evaluation of trainee therapists' abilities may be experienced as evaluation of the whole self. Consequently, training can potentially have a substantial impact on trainees' wellbeing.

Whilst participants' stories typically featured some aspect of training as motivation for seeking therapy, only Emma described any anger regarding this. She recalled making changes after failing a placement, because 'they literally put a gun to my head.' Kelley-Lainé (2003) suggests metaphors allow verbal expression of psychic pain. Although Emma employed a jovial tone when relating this story, her metaphor suggests a lack of choice or control. 
In addition to providing support through the stressors of training, participants described how therapy was important in their personal development:

We've all got things in our experience, in our history, that influence the way we are as people, but actually if we had them out in the open a bit more we might be able to give up some of the...traps that we fall into (Lilly)

Many participants also thought it was important to experience the 'client role,' suggesting an ethical obligation to "practice what you preach" (Ivey and Waldeck 2013: 3). However, Liz noted 'you don't expect surgeons here to have gone through surgery, you know, to empathise with the experience of what it's like to go through surgery.'

The cost of therapy featured within a number of participants' stories, with a shared narrative regarding the financial impact. Although some courses provided a budget for personal therapy, not all participants chose to utilise this. Helen personally funded her therapy, as 'when you're on the course, everything is being monitored and evaluated and it kind of felt like that might be just another thing.' Trainees may feel there is an expectation from their course as to what competencies should develop from accessing personal therapy, considering all other activities are monitored and evaluated.

\section{Chapter Two: Stigma of therapy - 'Oh my god it's so shameful' (Sophie)}

Stigma was a significant character in the majority of participants' journeys, whose presence was felt because 'we're clinical psychologists, we're the experts, we don't need therapy' (Annie). Jen reflected how dichotomous positions, or 'othering,' protected mental health professionals from considering they could be in their client's position. She posited, 'I think it's this quite black and white assumption that gets made about strength and weaknesses, and cared for and caring.' Richards (2010) discusses the dichotomy of 'us' and 'them' within mental health services, which implies individuals seeking mental health support are different, even abnormal. For clinicians, positioning themselves as separate to clients may reassert their own sanity and power (MacCallum 2002). Consequently, any movement towards the 'other' group could carry feelings of powerlessness, fear and shame.

A key event in Rachel's narrative was seeing another client leaving her therapist's house and wondering if they were an 'actual patient' with 'proper problems.' Although she used a jocular tone, this suggests a therapist's motivations for seeking therapy may differ to a non-therapist client's. However, Lavender (2003) describes how psychological difficulties exist on a continuum; consequently therapists are not "categorically different" (15) from clients.

Participants described fearing judgement from their therapist, particularly in terms of their competence as a clinical psychologist. Helen thought 'she's gonna think you're a psychologist, you shouldn't have these issues.' There was also a narrative shared by several participants regarding a sense of judgement from 'the course,' in response to their use of therapy. Emma indicated feeling 'beneath' her peers for accessing therapy, whilst Mary noted her course 'sold it' as professional development, which 'makes you think there's something wrong with saying you're going for therapy.'

These narratives suggest participants felt that accessing therapy was indicative of a weakness, which impacted on their suitability as a therapist. Research indicates many who choose to train as a therapist have their own psychological wounds (Barnett 2007, Wheeler 2002), which can enhance their effectiveness provided those wounds are sufficiently understood (Cain 2000, Gelso and Hayes 2007). However authors also note concerns of the potential stigma, or judgment of their competence, if therapists disclosed the details of those wounds (Zerubavel and O'Dougherty-Wright 2012). It could be that this affects therapists' abilities to reflect and attend to personal 'wounds,' if it does not feel safe to do so. 


\section{Chapter Three: The therapy process - 'Scary but exciting' (Holly)}

Many participants described waiting until 'crisis point' to undertake their therapy journey; 'I had to have that point where I kind of started to fall apart a bit before I could go' (Helen). These crises included events such as 'panic attacks,' 'an eating disorder,' and 'feeling suicidal.' Words such as 'awkward,' 'scary, 'exciting' and 'claustrophobic' were used to describe the initial stages of therapy.

All participants contributed to a shared narrative of the therapeutic relationship as key to enabling change on both a personal and professional level. Emma compared therapy to an 'attachment process' which facilitates self-knowledge and affect regulation. Words such as containment,' 'consistency and 'predictability' were used to describe positive therapeutic relationships. However the character of the therapist sometimes changed within participants' stories, as participants became 'conscious of affecting' (Rachel) him/her, and could 'hold back a little bit' (Holly).

Despite experiencing therapy positively overall, participants described a number of difficult emotions throughout their journey in response to being 'open and vulnerable' (Mary). Participants felt 'pissed off' (Liz) and 'absolutely hated her' (Annie). These responses may be a reaction to their therapist's interpretations, or a defence against feelings aroused by the new attachment (Farber, Lippert, and Nevas 1995). Defence mechanisms are described as unconscious reactions to stress or anxiety, in order to protect the self (Lemma 2003). If a therapist appears to confirm the trainee's 'need' for therapy, this may be experienced as confirmation of their inner weakness or failings.

Participants described a number of emotions they experienced during their therapy journey. Two participants utilised the same metaphor, but in contrasting ways. Liz expressed anger towards her therapist appearing 'self-satisfied' when Liz cried, because 'I've obviously hit the nail on the head.' Conversely, Lilly's therapy lacked 'those things that people say that absolutely dissolve you into tears because they hit the nail on the head.' This imagery suggests a precise and deliberate action performed by the therapist to the client, which could relate to the medical model of psychological disorder whereby therapy is the treatment delivered by the therapist to the client (Macran et al. 1999).

A number of fears were described by participants, such as being negatively judged for the content of their thoughts. Liz also discussed the difficulties in knowing the 'rules' of therapy and wanting to be a 'good client.' Some participants described negative aspects of their therapy journey, including deterioration in sleep, mood and anxiety. Sophie outlined the potential therapy trajectory:

Start with like honeymoon period, it's fab, then this is a load of shit, it's making me feel like crap, you're not changing my life at all...and then if they can persevere with that...they won't go up to honeymoon period again, they'll get to realistic.

The ending was a significant event within the therapy journey, and was experienced in different ways. Participants agreed it was difficult to 'know' the ending. The tone of these narratives was often wistful or sad, with Helen likening the ending to 'bereavement.' Liz highlighted a potential danger in accessing a short course of therapy, as 'she'd kind of dug all this stuff up and now was just trying to pack it back down again in time to finish in 12 weeks.'

\section{Chapter Four: Impact of therapy - 'I became a much better therapist' (Jen)}

Throughout their stories, participants described a number of ways in which therapy had impacted them personally and professionally. Several participants noted seeking more supportive friendships, and taking 'responsibility and ownership for feelings' (Holly). There were also changes in participants' relationships with themselves; they described feeling 'happier with 
me' (Annie). Liz, Annie and Mary commented on the experience of being listened to, when usually taking the role of listener.

All participants noted a substantial impact on their professional identity and clinical practice. This particularly arose from experiencing the client role and gaining 'insight to how vulnerable you can feel, and how exposed' (Lilly). This allowed participants to reflect on different aspects of therapy, particularly how the therapeutic relationship did not rely on 'using fancy words or models' (Helen). This also led participants to be more flexible, and attend to consistency within the therapy frame.

Whilst all participants noted positive impacts on their clinical work, some also noticed potentially negative effects. Jen's own story could lead her to become frustrated with clients; 'l've had to do all the hard work, you damn well should have to as well!' Both Mary and Jen reflected on the potential risk to 'try and do what worked for you, for your client' (Mary). The majority described changing their clinical practice in response to what was helpful/unhelpful in their own therapy. This implies an assumption that clients would have similar preferences, rather than creating "a new therapy for each patient" (Yalom 2002: 34), guided by each client's needs.

A key event in some participants' stories was realising 'I'm not just this special person that she sees just for me' (Rachel). Liz also described the 'conveyor belt' of clients where 'you're herded out and the next one comes in,' whilst Lilly noted:

You ring the doorbell, and how long does it take them to answer the doorbell, and why aren't they answering....who's in there and why, why are you keep-, I'm important, or who's more important than me?

These stories and imagery all relate to a sense of worth or value, as perceived by the therapist. This led participants to reflect on the power of their own relationships with clients.

The different experiences during participants' journeys led to an increase in professional confidence and a sense that 'my patient outcomes were so much better' (Emma). Helen found therapy beneficial in building her emotional resilience, whilst Jen suggested 'the more open we can be to ourselves, the more of ourselves there will be to bring into the room, and therefore the greater our capacity will be to imagine others' distress.' Mary also stated 'we owe it to the patients to have been able to at least know our own weaknesses or vulnerabilities and not put them on them.'

\section{Discussion}

All participants indicated personal therapy positively influenced them and their clinical work. Participants suggested their experiences allowed them to become better therapists, and that similar opportunities should be available to all trainee clinical psychologists.

Personal therapy can complement training as a therapist, and encourage personal and professional development (Norcross 2005). However, a number of participants described training itself as a significant factor in seeking therapy. Training as a clinical psychologist is typically stressful, as trainees are required to undertake emotive work, attend teaching, and perform academically (Schwartz-Mette 2009). Participants' suggestion that therapy was necessary in order to cope with these demands could imply course-provided support is inadequate for some trainees. Alternatively, as indicated by the participants in this study, trainees may feel unable to utilise support through the training course due to the evaluative nature of training and fear of negative appraisal.

Participants described a feeling of shame concerning accessing therapy as a trainee therapist, irrespective of their motivation for seeking it. Weiss (2004) discusses the attitude that "psychotherapists should be the prototypes of mental health," and the consequent fears of being 
considered "emotionally unstable or inadequate" (96). Authors have suggested therapists may feel threatened by needing help (Geller, Norcross, and Orlinsky 2005) and feel an expectation to be "superhuman" (Farber 2000: 343). This may be particularly so for trainee therapists, as they are regularly evaluated. Seeking support may indicate strengths in self-awareness and resilience (Wicks 2008). The BPS (2009) states psychologists should seek assistance if personal problems arise which may affect their work. However, participants' responses suggest a narrative within the profession that it is unacceptable, even shameful, to experience feelings that clients present with. This may impact on the likelihood of trainee therapists seeking help, or disclosing any difficulties, with a potentially negative impact on both their own wellbeing, and their clinical work.

The shame described by participants is indicative of a wider stigma regarding mental health difficulties (Corrigan 2004). Although campaigns such as Time to Change (2008) aim to reduce this, Richards (2010) suggests their approach reinforces narratives that those accessing mental health services are 'different.' Whilst it seems logical to state that this us-and-them dichotomy should be diminished, it may serve several purposes. Holding clients apart from oneself may allow therapists to contain clients' distress whilst remaining confident in their own wellbeing (Cain 2000). There may also be a function for clients in portraying therapists as "superhuman," in order to trust them with their own difficulties and "know they can cope with whatever the pain is" (Youngson, Hames, and Holley 2009: 67). These factors should be kept in mind when considering how to reduce the perceived inequalities between 'us' and 'them.'

\section{Limitations}

Several recruitment factors narrowed the sampling pool, such as courses not retaining contact information for past trainees. The sample size reflected a low response rate, and participants were self-selecting, therefore their experiences may differ from individuals who chose not to participate. There were also differences between participants that may have affected their experiences, such as their model or duration of therapy, and whether they had accessed therapy prior to training. However, participants expressed many similar narratives, suggesting a core of shared themes. Although the findings of this study cannot be applied to whole populations, they provide important considerations for future research and in supporting the personal and professional development of clinicians.

A significant limitation of the study is the gender bias; all participants were female. Whilst this is likely due to the higher proportion of females within the profession, narratives of male trainees accessing personal therapy may differ.

\section{Implications and future research}

These findings have several implications for clinical psychology training courses. All participants emphasised the positive role of personal therapy in developing their clinical skills, therefore its inclusion in training could be further explored. It would be valuable to explore participants' claims their personal therapy made them a 'better clinician,' although this has proved difficult to measure in previous research.

Participants' responses suggest some difficulties within the current support available during training. Training courses should consider the provision of external sources of support, such as personal therapy, or other confidential options. Currently, support for trainees differs between courses, although the BPS and Health and Care Professions Council provide objective and regulatory input as required. Future research could explore the sources of support available to, and utilised by, trainee clinical psychologists. It would also be informative for future research to include longitudinal studies with trainees throughout training, to capture any experiences of psychological difficulties and their coping, including use of personal therapy. Regular measures, both quantitative and qualitative, of clinical skills and confidence could also be collected from service users and trainees, to explore correlations between different aspects of clinical competence and the trainee's own wellbeing and self-awareness. 
There are a number of explicit conversations between training courses and trainees that may be beneficial to facilitate. This includes: the likelihood of experiencing psychological distress at times; the training course's position in relation to personal therapy, including funding; the possible consequences (both positive and negative) of personal therapy. Course staff could provide reflection and advice on aspects such as choosing models/therapists, the timing of therapy, and integrating the experience into their professional identity. It may be that there are particular times during training where there is more time or space for reflection, or where additional support would be most beneficial. Participants also discussed a lack of opportunity to discuss how to integrate their own personal therapy experiences into their work as a clinician, which training courses could aim to provide.

There are also implications for the clinical psychology profession as a whole. The stigma surrounding personal therapy is concerning, and may also reflect a societal attitude towards those accessing mental health services (Corrigan 2004). The positives in seeking support for personal and professional distress or development should be emphasised. As Youngson, Hames, and Holley (2009) state, we should be aiming for "a mutuality that, in reality, sees, believes and acts as if we are all on a continuum that means that at different times and stages in our lives sometimes we are the helper, and sometimes the helped" (63). Further research exploring the potential stigma for trainee clinical psychologists in both accessing therapy and disclosing psychological distress would develop understanding of these conflicts.

\section{Conclusion}

This study suggests personal therapy can provide valuable support to trainee clinical psychologists, including managing the stressors of clinical training. All but one participant described a sense of shame in accessing therapy as a trainee clinical psychologist, feeling they should be 'more sorted. The therapy process can also lead to difficult emotions, and affect participants' sleep, mood and relationships. This has implications for the profession as a whole, and its approach to members' mental health and self-care.

\section{Acknowledgements}

We would like to thank the ten individuals who shared their stories with us. 


\section{References}

Atkinson, P. (2006) 'Personal therapy in the training of therapists'. European Journal of Psychotherapy and Counselling 8 (4), 407-410 doi: 10.1080/13642530601038055

Barnett, M. (2007) "What brings you here?" An exploration of the unconscious motivations of those who choose to train and work as psychotherapists and counsellors'. Psychodynamic Practice 13 (3), 257-274. doi: 10.1080/14753630701455796

Bellows, K. F. (2007) 'Psychotherapists' personal psychotherapy and its perceived influence on clinical practice'. Bulletin of the Meninger Clinic 71 (3), 204-226. doi: 10.1521/bumc.2007.71.3.204

Bike, D. H., Norcross, J. C., and Schatz, D. M. (2009) 'Processes and outcomes of psychotherapists' personal therapy: Replication and extension 20 years later'. Psychotherapy Theory, Research, Practice, Training 46 (1), 19-31. doi: $\underline{10.1037 / \mathrm{a} 0015139}$

British Psychological Society (2002) Criteria for the Accreditation of Postgraduate Training Programmes in Clinical Psychology. Leicester: British Psychological Society.

British Psychological Society. (2006) Division of Counselling Psychology. Professional practice guidelines. Leicester: BPS. Available from www.bps.org.uk/sites/default/files/documents/professional practice guidelines division of counselling psychology.pdf [15 December 2014]

British Psychological Society. (2009) Code of Ethics and Conduct. Leicester: BPS. Available from <http://www.bps.org.uk/what-we-do/ethics-standards/ethics-standards $>$ [28 April 2014]

British Psychological Society. (2013) The Alternative Handbook for Postgraduate Training Courses in Clinical Psychology: 2013 Entry. Leicester: British Psychological Society

British Psychological Society: Division of Clinical Psychology. (2015) Personal Therapy. [online] available from http://www.bps.org.uk/networks-and-communities/membermicrosite/division-clinical-psychology/personal-therapy [20 November 2015]

Byatt, A. S. (2000) On Histories and Stories: Selected Essays. London: Chatto and Windus

Cain, N. R. (2000) 'Psychotherapists with personal histories of psychiatric hospitalisation: Countertransference in wounded healers'. Psychiatric Rehabilitation Journal 24 (1), 22 28 doi: $10.1037 / \mathrm{h} 0095127$

Clark, M. M. (1986) 'Personal therapy: A review of empirical research'. Professional Psychology: Research and Practice 17 (6), 541-543 doi: 10.1037/0735-7028.17.6.541

Coffey, A. (1999) The Ethnographic Self: Fieldwork and the Representation of Identity. London: Sage

Corrigan, P. (2004) 'How stigma interferes with mental health care'. American Psychologist 59 (7), 614-625 doi: 10.1037/0003-066X.59.7.614

Crossley, M. L. (2000) Introducing Narrative Psychology: Self, Trauma and the Construction of Meaning. Buckingham: Open University Press 
Daw, B., and Joseph, S. (2007) 'Qualified therapists' experience of personal therapy'. Counselling and Psychotherapy Research 7 (4), 227-232 doi: 10.1080/14733140701709064

Farber, N. K. (2000) 'Trainees' attitudes toward seeking psychotherapy scale: Development and validation of a research instrument'. Psychotherapy: Theory, Research, Practice, Training 37 (4), 341-353 doi: 10.1037/0033-3204.37.4.341

Farber, B. A., Lippert, R. A., and Nevas, D. B. (1995) 'The therapist as attachment figure'. Psychotherapy, 32 (2), 204-212. doi: 10.1037/0033-3204.32.2.204

Geller, J. D., Norcross, J. C., and Orlinsky, D. E. (2005) 'The question of personal therapy: Introduction and prospectus'. in The Psychotherapist's Own Psychotherapy: Patient and Clinician Perspectives ed by ed by Geller, J. D., Norcross, J.C., and Orlinsky, D. E. New York: Oxford University Press, 3-14

Gelso, C. J., and Hayes, J. A. (2007) Countertransference and the Therapist's Inner Experience: Perils and Possibilities. Mahwah, N.J.: Erlbaum

Gold, S. H., and Hilsenroth, M. J. (2009) 'Effects of graduate clinicians' personal therapy on therapeutic alliance'. Clinical Psychology \& Psychotherapy 16 (3), 159-171 doi: $\underline{10.1002 / \mathrm{cpp} .612}$

Greenspan, M., and Kulish, N. M. (1985) 'Factors in premature termination in long-term psychotherapy'. Psychotherapy: Theory, Research, Practice, Training 22 (1), 75-82 doi: $\underline{10.1037 / h 0088529}$

Grimmer, A., and Tribe, R. (2001) 'Counselling psychologists' perceptions of the impact of mandatory personal therapy on professional development--an exploratory study'. Counselling Psychology Quarterly 14 (4), 287-301 doi: 10.1080/09515070110101469

Holzman, L. A., Searight, H. R., and Hughes, H. M. (1996) 'Clinical psychology graduate students and personal psychotherapy: Results of an exploratory survey'. Professional Psychology: Research and Practice 27 (1), 98-101 doi: 10.1037/0735-7028.27.1.98

Ivey, G., and Waldeck, C. (2013) 'Trainee clinical psychologists' experience of mandatory personal psychotherapy in the context of professional training'. Asia Pacific Journal of Counselling and Psychotherapy 5 (1), 87-98 doi: 10.1080/21507686.2013.833525

Kelley-Lainé, K. (2003) "'The metaphors we live by"'-. International Forum of Psychoanalysis 12 (1), 38-43 doi: $10.1080 / 083037060310005232$

Kumari, N. (2011) 'Personal therapy as a mandatory requirement for counselling psychologists in training: A qualitative study of the impact of therapy on trainees' personal and professional development'. Counselling Psychology Quarterly 24 (3), 211-232 doi: $\underline{10.1080 / 09515070903335000}$

Lavender, T. (2003) 'Redressing the balance: The place, history and future of reflective practice in clinical training'. Clinical Psychology [online] 27, 11-15. Available from http://www.psychminded.co.uk/clinical-psychology-issue-27-july-2003/ [7 December 2015]

Lemma, A. (2003) Introduction to the Practice of Psychoanalytic Psychotherapy. Chichester, UK: John Wiley \& Sons 
Macaskill, A. (1999) 'Personal therapy as a training requirement: The lack of supporting evidence'. in Controversies in Psychotherapy and Counselling. ed by Feltham, C. London: Sage, 142-155

Macaskill, N. D., and Macaskill, A. (1992) 'Psychotherapists-in-training evaluate their personal therapy: Results of a UK survey'. British Journal of Psychotherapy 9 (2), 133-138 doi: 10.1111/j.1752-0118.1992.tb01211.x

MacCallum, E. J. (2002) 'Othering and psychiatric nursing'. Journal of Psychiatric and Mental Health Nursing 9 (1), 87-94 doi: 10.1046/j.1351-0126.2001.00449.x

Macran, S., Ross, H., Hardy, G. E., and Shapiro, D. A. (1999) 'The importance of considering clients' perspectives in psychotherapy research'. Journal of Mental Health 8 (4), 325337 doi: $10.1080 / 09638239917256$

Macran, S., and Shapiro, D. A. (1998) 'The role of personal therapy for therapists: A review'. British Journal of Medical Psychology 71 (1), 13-25 doi: 10.1111/j.20448341.1998.tb01364.x

Malikiosi-Loizos, L. (2013) 'Personal Therapy for Future Therapists: Reflections on a Still Debated Issue'. The European Journal of Counselling Psychology 2 (1), 33-50 doi:10.5964/ejcop.v2i1.4

Moller, N. P., Timms, J., and Alilovic, K. (2009) 'Risky business or safety net? Trainee perceptions of personal therapy: a qualitative thematic analysis'. European Journal of Psychotherapy and Counselling 11 (4), 369-384 doi: 10.1080/13642530903444803

Murphy, D. (2005) 'A qualitative study into the experience of mandatory personal therapy during training'. Counselling and Psychotherapy Research 5 (1), 27-32 doi: $\underline{10.1080 / 14733140512331343868}$

Murray, M. (2008) 'Narrative psychology'. in Qualitative Psychology: A Practical Guide to Research Methods.2nd edn. ed by Smith, J. A. London: Sage, 111-132

Nel, P. W., Pezzolesi, C., and Stott, D. J. (2012). 'How did we learn best? A retrospective survey of clinical psychology training in the United Kingdom'. Journal of Clinical Psychology 68 (9), 1058-1073 doi: 10.1002/jclp.21882

Norcross, J. C. (2005) 'The psychotherapist's own psychotherapy: Educating and developing psychologists'. American Psychologist 60 (8), 840-850 doi: 10.1037/0003$\underline{066 X .60 .8 .840}$

Norcross, J. C., Dryden, W., and DeMichele, J. T. (1992) 'British clinical psychologists and personal therapy: III. What's good for the goose?' Clinical Psychology Forum 44, 29-33

Norcross, J. C., and Guy Jr., J. D. (eds.) (2007) Leaving It at the Office: A Guide to Psychotherapist Self-Care. New York, USA: Guildford Press

Orlinsky, D. E., Norcross, J. C., Ronnestad, M. H., and Wiseman, H. (2005) 'Outcomes and impacts of the psychotherapist's own psychotherapy'. in The Psychotherapist's Own Psychotherapy: Patient and Clinician Perspectives. ed by Geller, J. D., Norcross, J.C., and Orlinsky, D. E. New York: Oxford University Press, 214-234

Rake, C. (2009) 'Therapy and personal development'. in Personal Development and Clinical Psychology. ed by Hughes, J., and Youngson, S. Chichester, UK: BPS Blackwell, 108123 
Rake, C., and Paley, G. (2009) 'Personal therapy for psychotherapists: The impact on therapeutic practice. A qualitative study using interpretative phenomenological analysis'. Psychodynamic Practice 15 (3), 275-294 doi: 10.1080/14753630903024481

Richards, C. (2010) 'Them and us' in mental health services. The Psychologist 23 (1), 40-41

Riessman, C. K. (1993) Narrative Analysis. London: Sage

Riessman, C. K. (2008) Narrative Methods for the Human Sciences. California, USA: Sage

Rizq, R., and Target, M. (2010) "We had a constant battle": The role of attachment status in counselling psychologists' experiences of personal therapy: Some results from a mixedmethods study'. Counselling Psychology Quarterly 23 (4), 343-369 doi: $\underline{10.1080 / 09515070.2010 .534327}$

Schwartz-Mette, R. A. (2009) 'Challenges in addressing graduate student impairment in academic professional psychology programs'. Ethics \& Behaviour 19 (2), 91-102 doi: $\underline{10.1080 / 10508420902768973}$

Sheikh, A. I., Milne, D. L., and MacGregor, B. V. (2007) A model of personal professional development in the systematic training of clinical psychologists. Clinical Psychology and Psychotherapy 14 (4), 278-287 doi: 10.1002/cpp.540

Squire, C. (2008) 'Experience-centred and culturally-orientated approaches to narrative'. in Doing Narrative Research. ed by Andrews, M., Squire, C., and Tamboukou, M. London: SAGE, 41-63

Sword, W. (1999) 'Accounting for presence of self: Reflections on doing qualitative research'. Qualitative Health Research 9 (2), 270-278 doi: 10.1177/104973299129121839

Thorne, B., and Dryden, W. (1991) 'Key issues in the training of counsellors'. in Training and Supervision for Counselling in Action. ed by Dryden, W. and Thorne, B. London: Sage, $1-14$

Time to Change. (2008) [online] Available from $<\underline{w w w . t i m e-t o-c h a n g e . o r g . u k />~[21 ~ A p r i l ~ 2014] ~}$

Timms, J. (2010) 'A taste of our own...therapy: Trainees' rationales for, and experiences of, personal therapy'. Clinical Psychology Forum 213, 34-39

Von Haenisch, C. (2011) 'How did compulsory personal therapy during counselling training influence personal and professional development?' Counselling and Psychotherapy Research 11 (2), 148-155 doi: 10.1080/14733145.2010.485693

Weatherhead, S. (2011) 'Narrative Analysis: An often overlooked approach'. Clinical Psychology Forum 218, 47-52

Weiss, L. (2004) Therapist's Guide to Self-Care. New York: Brunner-Routledge

Wertz, F. J., Charmaz, K., McMullen, L. M., Josselson, R., Anderson, R., and McSpadden, E. (eds.) (2011) Five Ways of Doing Qualitative Analysis. New York: Guilford Press

Wheeler, S. (2002) 'Nature or nurture: Are therapists born or trained?' Psychodynamic Practice 8 (4), 427-441 doi: 10.1080/1353333021000038809

Wicks, R. J. (2008) The Resilient Clinician. New York, USA: Oxford University Press 
Wiseman, H., and Shefler, G. (2001) 'Experienced psychoanalytically oriented therapists' narrative accounts of their personal therapy: Impacts on professional and personal development'. Psychotherapy 38 (2), 129-141 doi: 10.1037/0033-3204.38.2.129

Wosket, V. (1999) The Therapeutic Use of Self. London: Brunner-Routledge

Yalom, I. D. (2002) The Gift of Therapy: An Open Letter to a New Generation of Therapists and their Patients. London, UK: Piatkus

Yardly, L. (2008) 'Demonstrating validity in qualitative psychology'. in Qualitative Psychology: A practical guide to research methods. 2nd edn. ed by Smith, J. A. London: Sage, 235251

Youngson, S., Hames, R., and Holley, T. (2009) 'If they don't know themselves, they can't help you find yourself, can they really?"' in Personal Development and Clinical Psychology, ed by Hughes, J., and Youngson, S. Chichester, UK: BPS Blackwell, 62-74

Zerubavel, N., and Wright, M. O'D. (2012) 'The dilemma of the wounded healer'. Psychotherapy 49 (4), 482-491 doi: 10.1037/a0027824 